\title{
XXXIII SEMINARIO INTERUNIVERSITARIO DE TEORÍA DE LA EDUCACIÓN
}

Celebrado en Sevilla, los días 25 y 26 de noviembre de 2014, organizado por el Departamento de Teoría e Historia de la Educación y Pedagogía Social de la Universidad de Sevilla en colaboración con la Red Académica de Teoría de la Educación. Bajo el título Cultura emprendedora y educación, cincuenta y cuatro profesores expertos en esta temática, pertenecientes a las diferentes universidades españolas que integran la Red, han analizado el fomento de la cultura emprendedora, su problemática y desafíos educativos, especialmente en Educación Superior. Las recomendaciones del Consejo de Europa sobre la dinamización de la cultura del emprendimiento como motor para el crecimiento económico y el empleo y la existencia, a escala nacional y regional, de Planes para el fomento de la cultura emprendedora, evidencian el creciente interés de las políticas educativas en materia de desarrollo del espíritu emprendedor y la cultura emprendedora en las distintas etapas formativas.

Siguiendo las pautas de trabajo de anteriores SITE, las ponencias invitadas y adendas presentadas han permitido clarificar y sistematizar esta cuestión a través, entre otros, del análisis conceptual que estos términos comportan, el estudio crítico de los fundamentos teórico-educativos de los programas y acciones ligadas al fomento del emprendimiento, así como el análisis crítico y descriptivo de las iniciativas y experiencias educativas existentes.

Dentro de los planes de difusión e intercambio de resultados de la producción científica de la Red Académica sITE, la Red publica anualmente una obra monográfica vinculada a la temática del Seminario. Con motivo de la trigésimo tercera edición del SITE, la Editorial Universidad de Sevilla asumió el compromiso de edición de las actas del Seminario con la obra coordinada por Núñez Cubero, L. (dir.) (2015) Cultura Emprendedora y Educación. Sevilla, Editorial Universidad de Sevilla. ISBN: 978-84-472-1606-2.

Las sesiones de trabajo se han desarrollado a partir de tres ponencias invitadas y las correspondientes adendas presentadas a cada una de ellas. La Ponencia Inaugural, titulada La cultura emprendedora como objetivo educativo, fue coordinada por el profesor José Vicente Peña Calvo (Universidad de Oviedo), en colaboración con los investigadores Antonio Cárdenas Gutiérrez (Universidad de Sevilla), Alejandro Rodríguez Martín (Universidad de Oviedo) y Encarnación Sánchez Lissen (Universidad de Sevilla). Para los ponentes, situar el emprendimiento como objetivo educativo implica "un proceso largo, de sensibilización, de concienciación que supone atender a las características sociales, económicas, empresariales, políticas y educativas".

El desarrollo del talento emprendedor: estrategias y buenas prácticas es el título de la segunda ponencia invitada, coordinada por la profesora Pilar Pineda Herrero (Universidad Autónoma de Barcelona), en colaboración con los investigadores 
Gabriel Carmona Orantes (Universidad de Granada) y la profesora Anna Planas (Universidad de Gerona). Los ponentes tomaron como referencia el marco legislativo para la educación del talento emprendedor, las investigaciones más recientes sobre las capacidades creativas y ayudaron a contextualizar buenas prácticas en educación para la creatividad emprendedora. La mirada crítica no ha estado ausente en la segunda ponencia, cuando nos alertaron del "temor a que se utilice el emprendimiento como mecanismo para legitimar políticas neoliberales de precarización laboral, y a que su promoción exacerbada nos lleve a una consagración del individualismo y derive en una sociedad aún más competitiva”.

Las aportaciones de la tercera ponencia invitada, coordinada por la profesora Mar Lorenzo (Universidad de Santiago de Compostela), en colaboración con las investigadoras Amparo Civila (Universidad de Málaga), Carolina FernándezSalinero (Universidad Complutense de Madrid) y Concepción Naval (Universidad de Navarra), se ocuparon de analizar las diferentes iniciativas, planes y programas que se están llevando a cabo en pos de la cultura emprendedora. Bajo el título: Programas de emprendimiento en contextos educativos formales la ponencia de clausura revisó los programas existentes, características, destinatarios, enfoques metodológicos y estrategias de evaluación en los que se dichos programas se apoyan. La ponencia insistió en la idea de que para educar la competencia emprendedora es necesario promover "un ecosistema emprendedor en el mismo seno de la educación formal, avalado por un marco normativo de referencia, que comience a desarrollarse en los centros de educación básica, a través del diseño y puesta en marcha de programas de emprendimiento, y que adquiera un protagonismo mayor en el contexto universitario".

Por último, nos gustaría señalar que, junto a las tres ponencia marco, se presentaron treinta y una adendas al XXXIII SITE, cuyos resúmenes pueden leerse en http://site2014.us.es y cuyos textos completos pueden consultarse en la publicación referenciada anteriormente. 